\title{
Strategies to Reduce Metal-Ion Exposure to Humans and Environment by Non-Thermal Plasma Technology
}

\author{
Namita jain ${ }^{1}$ and Amulya Ranjan ${ }^{2}$ \\ Benezir Govt. College, Bhopal (M.P.) India
}

\begin{abstract}
In this paper we study on the report on heavy metal ions pollution and strategies to reduce metal ion exposure to human and environment by using non-thermal plasma technology. We find that plasma pollution control technology is more significant than others technology because of its advantages such as smaller space volume, lower cost, higher treatment and energy efficiencies. It is found that this technology is also effective to reduce water pollution.
\end{abstract}

\section{Introduction}

Every human being is composed of chemicals both simple and intricate. All that we breathe, eat, drink is chemical and that which we prepare is also chemical. A body requires about 25 kilograms of air a day for its requirement for oxygen. If this is multiplied with world population of 8 billion then 2000 billion $\mathrm{Kg}$ of air are breathed per day by human beings. It is reported that more than a million people are added to the population of the world every five days. The human life has added hundreds of pollutants in the atmosphere the important are so2, co, hydrocarbons oxides of nitrogen, solid particles and heat. With the advent of industrialization, the presence of obnoxious gases and metal particles have increased tremendously in the atmosphere ${ }^{1}$.

\subsection{Toxicity of Metal: -}

The word toxic is taken from the Greek word toxon ["bow"] and toxicon or pharmicon ["arrow poison"]. Toxicity can be defined as branch of science which deals with the study of adverse and harmful effects of chemical agents on any biological system. A list of toxic metals can be prepared by knowing the metals used in industry, agriculture, cosmetics, household usage, food processing and medicine. In periodic table there are 105 elements out of which 17 metals have been found to be very toxic.

\subsection{Toxic metals in environment: -}

\begin{tabular}{|c|c|c|c|c|c|c|c|c|c|c|}
\hline $\mathrm{V}$ & $\mathrm{Cr}$ & $\mathrm{Mn}$ & $\mathrm{Fe}$ & Co & $\mathrm{Ni}$ & $\mathrm{Cu}$ & $\mathrm{Zn}$ & & & $\begin{array}{l}\text { As } \\
\text { Metalloid }\end{array}$ \\
\hline & & & & & & $\mathrm{Ag}$ & $\mathrm{Cd}$ & In & $\mathrm{Sn}$ & $\begin{array}{l}\text { Sb } \\
\text { Metalloid }\end{array}$ \\
\hline
\end{tabular}

Toxicology is following types; clinical toxicology, industrial toxicology, forensic toxicology, environmental toxicology and economic toxicology. The toxicity of metals depends on the inherent capacity of metal to affect adversely and biological activity. Toxic metals change the biological structures and systems into deformity in the body or finally death. Mostly metals are toxic at higher concentrations and some are lethal even at very low concentrations. Although heavy metals within limits are essential for aquatic organisms, plants as well as humans to survive and functions ${ }^{1}$.

\section{Environmental Pollution Due To Toxic Metals}

There is difference between environmental contamination and pollution. Contamination is the release of the metal into environment at measurable concentrations, while pollution implies the manifestation of measurable effects produced by metals on the living systems. Toxic metals to a large extent, are depressed in the biosphere through industrial effluents, organic wastes, refuse burning, transport and power generation.

Bhabha atomic research center [BARC], Mumbai, has carried out investigations to analysis the content of metal in food samples, water, vegetable etc. in and around Mumbai. Blood and urine samples of city dwellers (Gujarat) were analyzed for the content of zinc, manganese, cobalt, nickel, copper, chromium, and lead for assessing the base line levels for the general population. Nickel content in blood was found to be quite high and this was supposed to be due to the consumption of vegetable ghee or use of stainless steel utensils in cooking. Besides producing systematic poising, nickel is also known to cause cancer in humans. Nickel also produces skin diseases and ulcers. 


\section{Some Toxic Metals Poisoning}

In the modern life increasing use of metals has resulted in a variety of problems. We study some such type of toxic metals poisoning an industrial hazard ${ }^{5-9}$.

\subsection{Manganese Poisoning: -}

The researches at the industrial toxicology research center [ITRC], lucknow, in a series of experiments have concluded that manganese exerts toxic action on brain and other body organs such as liver, kidney and testis. They also have known that the enzyme succinate dehydrogenose (SDH) of the TCA or Kerbs cycles may be one of the main factors for the pathogenesis of manganese on SDH may lead to slow metabolism of the cell with consequent changes in cell physiology and finally cell death.

\subsection{Lead Poisoning: -}

Lead exposure comes mainly from three sources; Food, drinking water and ambient air. Lead hazard to human health and have a wide spread environmental pollutant. On a global basis, the major source of lead pollution is the combustion of gasoline to which ether tetraethyl or tetra methyl lead is added as an antiknock compound to increase the octane value ${ }^{6}$.

\subsection{Mercury Poisoning: -}

Mercury toxic effects in the nervous system which include anxiety, depression, lack of concentration and tremors. Mercury toxicity are found in fish, milk of buffaloes and cows grazing plants in some areas ${ }^{3-4}$.

\subsection{Cadmium Poisoning: -}

Cadmium is a non essential element and highly toxic to man and several other organism. Chronic poisoning may occur is occupationally non-exposed persons due to prolonged exposure to low concentration of cadmium.

\subsection{Vanadium Poisoning: -}

It is found that vanadium a potentially dangerous chemical pollutant that can play have with the productivity of plants, crops and in short with the entire agricultural system.

\section{Non-thermal plasma technology: -}

Non-thermal plasma sometimes called non-equilibrium or cold plasmas, have different electron, ion and neutral species temperature; the electrons have the highest temperature. Such plasmas are good sources of highly reactive oxidative and reductive radicals and plasma electron. These radicals decomposes the pollutants, fragments the large hydrocarbon in to smaller one ${ }^{2}$.

The non-thermal plasma is effective against the toxic metal pollution since energy is not required to heat all the particles to high temperature, non-thermal plasma technology can efficiently destroy toxic metal pollutants targeted by the hot electron.

Non-thermal plasma can be used to monitor the toxic pollutants of environment with high sensitivity. Nonthermal plasma pollutant monitors have demonstrated sensitivity of batter than one part per billion for lead, chromium, mercury and other toxic metals allowing better control of hazardous metal ion exposure to humans and environment.

\section{Non-thermal plasma reactor: -}

Non-thermal plasmas generated in large vacuum reactors. There are several types of non-thermal plasma reactors based on their discharge technique ${ }^{10}$. In these reactor Non-thermal plasma may be obtained by a diversity of electrical discharges such as corona discharge, micro hollow cathode discharge, atmospheric pressure plasma jet, gliding arc discharge, one atmospheric uniform glow discharge, dielectric barrier discharge, and plasma needle, all having important technological applications .the non-thermal plasma reactor uses the effects of static electricity.

The reactor is consisting of two electrodes separated by a void space that is lined with a dielectric material. This type of reactor is called. Dielectric-Barrier Discharge (DBD). In this reactor the discharge happened between two poles. The duration of discharge is measured in nanoseconds. The individual discharge cannot be seen with the human eye, but the overall effect produces a silent glow. In this reactor, the atoms are being separated from their molecules and forms the free radicals. Due to, the highly reactive nature, these free radicals quickly recombine with other atoms or molecules to form new compounds. 


\section{Application Of Non-Thermal Plasma Technology To Reduce Metal Toxic}

As we knows that plasma is a mixture of positively charged particles(ions), negatively charged particles(electrons) and uncharged particles and high concentrated free radicals, atomic or molecular fragments that are very chemically reactive. These free radicals can quickly overwhelm the natural defenses of living organisms, leading to their destruction. Because plasma can easily produce 500000000000 free radicals per cubic centimeter volume, it can be efficient decontamination agent. Using oxygen as an example, the normal state of oxygen is a molecule containing two oxygen atoms. In the reactor, this oxygen molecule splits into free radicals. These oxygen radicals react with other compounds of toxic metals. For example, $\mathrm{O}^{+}$reacts with elemental mercury $(\mathrm{Hg})$ to form mercury oxide $(\mathrm{HgO})$. Oxidizing elemental mercury changes it form a vapor to a solid phase.

It is evident from above discussion that cold plasmas can be effective for a number of applications such as decontaminate food back aging as well as surfaces exposed to biological war for agents striations' of heatsensitive medical tools. Cold plasmas are especially effective for above application because they can treat contaminated items respectively quickly.

Along with this plasmas are also effective because they can diffuse into complicated structures, such as endoscopes, in similar manner as ethylene oxide, but without that decontaminants undesirable toxicity. This novel property makes plasma decontamination more effective than method based on radiation beam \{e.g. Gamma rays, electrons, UV light $\}$ which are all limited by where the beam is directed.

Thus the development of cold atmosphere plasmas provides, us a new hope for destroying stubborn bacteria and viruses, both for defense and public health. This cold atmospheric plasma decontamination also provides considerable economic benefit. For example, the material cost of a decontamination unit for a hospital is likely to be at least ten times less expensive than comparable low-temperature decontamination system recently used in healthcare. It is evident from above discussion, both in terms of low cost and effectiveness, the future of plasma decontamination is bright ${ }^{6-8}$.

Plasma can also be used in vehicles to reduce pollution from conventional fossil fuel combustion by 'reforming' the fuel before it is burned, breaking it down in to compounds that burn more cleanly.

\section{Application Of Plasma For Industries And Commercial}

Plasma is used in various fields which is given below in table

\begin{tabular}{|c|c|c|c|c|}
\hline Processing & $\begin{array}{c}\text { Volume } \\
\text { Processing }\end{array}$ & $\begin{array}{l}\text { Radiation } \\
\text { Processing }\end{array}$ & $\begin{array}{c}\text { Energy } \\
\text { Converters }\end{array}$ & Medicine \\
\hline $\begin{array}{l}\text { 1. Surface processing } \\
\text { 2. Non equilibrium } \\
\text { (low pressure) } \\
\text { 3. Thermal (high } \\
\text { pressure) }\end{array}$ & $\begin{array}{l}\text { 1. Fuel gas } \\
\text { treatment } \\
\text { 2. Metal } \\
\text { recovery } \\
\text { 3. Waste } \\
\text { treatment }\end{array}$ & $\begin{array}{l}\text { 1. Water } \\
\text { purification } \\
\text { 2. Plant growth }\end{array}$ & $\begin{array}{l}\text { 1. MHD } \\
\text { Converters } \\
\text { 2. Thermionic } \\
\text { energy converters }\end{array}$ & $\begin{array}{l}\text { 1. Surface } \\
\text { treatment } \\
\text { 2. Instrument } \\
\text { sterilization }\end{array}$ \\
\hline
\end{tabular}

\section{Remarks}

Large number of cases had reported during last ten years regarding metals pollution specially heavy metals like mercury, lead, cadmium etc. in fishes and through them to human being. It appears that non- thermal plasma technology works to reduce heavy metal pollutants from emission. However the technology is still in the early development stage. It is remarked that this technology should be evaluated based on; (a) the removal or treatment efficiency and rates, (b) the energy efficiency of removal or treatments, (c) the pressure drop of devices, (d) the reusable material production rate.

\section{Conclusion}

As we know that there are many other technology to reduce toxic metals but the developing and implementing non-thermal plasma technology is needed very much. It could help restore and protect our environment, providing new cleaning methods and helping countries comply with environmental regulations. So in this paper we conclude that the non-thermal plasma technology is good pollutant reduction technology as compared to other traditional technologies because it does not produce waste and has wide industrial applications. There are various non-thermal plasma pollution control technology. Therefore, Depending on target pollutants and concentration of pollutant, different types of plasma process and integrated pollution control systems should be used. 


\section{Reference}

[1] Kudesia, V.P., Air Pollution, Acta Cinencia Indica, 1985,

[2] Bernie M. Penetrante, Shirly E. Schultheis, Non-thermal Plasma Technique For Pollution Control Part A \& B (NATO ASI series advanced science institute series spring-velag) 1993

[3] Komerwer, A.M., Asokan, K., Krishnamurthy, S., et al., Ind. J. Environ. Hlth. 20, (1978) 284

[4] Somayajulu, B.L.K. And Rama, Sci. 44, (1972) 207

[5] Romani rao I.V., Patil, H.R., and Haldar, B.C., Report from the institute of science, Bombay (1979)

[6] Handa B.K., Ind. J. Heridity, 11, (1979) 13

[7] Singbal SYS, Sanzgiri,S. \& gupta, R. Sen. Total mercury concentaration in the Arabian sea waters off the Indian coast. Ind. J. Mar. Sci. 7, (1978) 124

[8] Sanzgiri, S., Gupta, R. Sen. \& Singbal S.Y.S., Ind. J. Mar. Sci. 8, (1979) 252

[9] Bhandari L.M., Ind. J. Environ. Health, 15, (1973) 236

[10] Barker, R., Backer, K., U Kogelschatz, and K. Schoenbach, Non Equilibrium Air Plasmas At Atmospheric Pressure, (institute of physics publishing, London Bristol, Philadelphia, Tokyo, Beijing) 2005. 